ADUBAÇÃO VERDE DO FEIJOEIRO "DA SÊCA" COM FRVILHA-DE-VACA ( $\left.{ }^{(}\right)$. H. A. A. Mascarenhas, S. Miyasaka, L. D. DE Almeida, E. S. Freire ( ${ }^{2}$ ) e Milton Alcover. No Estado de São Paulo, raramente se tem usado como adubo verde a ervilha-de-vaca (Vigna sinensis L. Savi), mais conhecida pelo nome inglês de cow-pea. Neme $\left({ }^{3}\right)$ desaconselha seu emprêgo generalizado, por ser muito suscetível ao ataque de nematóides. Além disso, sua produção de massa verde é, em regra, muito menor que a de outras leguminosas adaptadas ao ambiente paulista, como a mucuna prêta (stizolobium sp.) e a Crotalaria juncea L., quando comparadas na época em que alcançam o desenvolvimento máximo. Todavia, quando não se pode esperar que as últimas leguminosas atinjam êsse ponto, a ervilha-de-vaca, que é muito mais precoce, pode competir favoràvelmente com elas.

Assim é que Mendes $\left({ }^{4}\right)$, em Piracicaba, semeando mucuna prêta e ervilha-de-vaca da variedade Irón no principio de outubro, verificou que a primeira começou a florescer 125 dias depois, ocasião em que produziu $2.224 \mathrm{~kg} /$ ha de matéria sêca com $75 \mathrm{~kg}$ de nitrogênio, ao passo que a segunda floresceu 61 dias após a semeação e produziu $2.280 \mathrm{~kg} /$ ha de matéria sêca com $69 \mathrm{~kg}$ de nitrogênio. Segundo êsse autor $\left({ }^{4}\right)$, no Estado de São Paulo a ervilha-de-vaca oferece ainda a vantagem de poder ser semeada no fim do verão ou no comêço do outono e de fornecer apreciável quantidade de massa vegetal.

Por êsses motivos, conduziu-se a experiência preliminar, cujos resultados são relatados na presente nota, na qual a adubação verde com ervilha-de-vaca foi testada na ausência e na presença de adubaçōes minerais com nitrogênio e potássio.

MAterial E MÉtodo - A experiência foi instalada na Estação Experimental de Capão Bonito, em solo Latosol Vermelho Escuro-Orto. A área aproveitada havia sido adubada com fertilizantes minerais nas culturas anteriores e tinha $\mathrm{pH} 5,0$.

\title{
( $\left.{ }^{1}\right)$ Recebida para publicaçśo em 20 de abril de 1967.
}

$\left({ }^{2}\right)$ Contratado pelo Conselho Nacional de Pesquisas, para colaborar com tecnicos do Instituto Agronômico. Sua co!aboração no presente trabalho foi prestada na apresentação e interprétação dos resultados obtidos.

${ }^{3}$ ) NEME, N. A. Leguminosas para adubos verdes e forragens. Campinas, Instituto Agronómico, 1959. 28p. (Boletim n." 109).

(4) MENDES, C. TEIXeira. Adubos verdes. São Paulo, Oficinas Gráficas Monteiro Lobato, 1922 , $68 \mathrm{p}$. 
O plano experimental constou de três níveis de $\mathrm{N}(0,1$ e 2$)$, dois de $\mathbf{K}\left(\begin{array}{lll}0 & \text { e } & 1\end{array}\right)$ e dois de adubação verde com ervilha-de-vaca $(0$ e 1$)$. Com êsses níveis, dever-se-ia formar um esquema fatorial $3 \times 2 \times 2$ para $\mathrm{N}, \mathrm{K}$ e $V$, șem repetiçóes. Todavia, devido a um equívoco, na instalação a distribuição dos canteiros não foi feita de modo adequado, de sorte que os resultados não foram analisados estatìsticamente.

Os níveis 0,1 e 2 de $\mathrm{N}$, na forma de sulfato de amônio, corresponderam a, respectivamente, 0,30 e $60 \mathrm{~kg} / \mathrm{ha}$; os dois de $\mathrm{K}_{2} \mathrm{O}$, como cloreto de potássio, a 0 e $30 \mathrm{~kg} / \mathrm{ha}$. Todos os canteiros receberam dose uniforme $\left(100 \mathrm{~kg} / \mathrm{ha}\right.$ de $\left.\mathrm{P}_{2} \mathrm{O}_{5}\right)$ de superfosfato simples.

A ervilha-de-vaca foi semeada, sem qualquer adubação, em 6 de outubro de 1965, e incorporada ao solo no dia 4 de fevereiro de 1966, ocasião em que sua produção de massa verde (dose $V_{1}$ ) atingiu 21 t/ha. $O$ plantio do feijoeiro, da variedade Pintado, foi efetuado a 15 de fevereiro de 1966. O fósforo e o potássio foram empregados na ocasiāo do plantio do feijoeiro, em sulcos situados cêrca de $5 \mathrm{~cm}$ ao lado dos destinados às sementes; o nitrogênio, em cobertura, ao terminar a emergência das plantas.

Os canteiros tiveram $16,80 \mathrm{~m}^{2}$. Nessa área é que se semeou e incorporou a ervilha-de-vaca. De feijão, foram plantadas sete fileiras de $6 \mathrm{~m}$, com o espaçamento de $40 \mathrm{~cm}$ entre elas e usando-se quatorze sementes por metro linear de fileira, para se aproveitarem sòmente as três fileiras centrais ou $7,20, \mathrm{~m}^{2}$.

Resultados - O tempo correu satisfatòriamente, com chuvas normais de fevereiro a abril e abaixo das normais em maio, na época da maturação. Conquanto os "stands" do feijoeiro tenham sido um pouco prejudicados pela adubação potássica e, apreciàvelmente, pela adubação verde, que provocou uma redução de $16 \%$, as produções de sementes (quadro 1) foram elevadas nos melhores tratamentos.

As respostas médias às doses 1 e 2 de nitrogênio corresponcleram a, respectivamente, $+309 \mathrm{e}+357 \mathrm{~kg} / \mathrm{ha}$, mas o comportamento dêsse elemento dependeu consideràvelmente da presença dos outros fatôres estudados. Efetivamente, enquanto o efeito médio das duas, doses atingiu $+597 \mathrm{~kg} / \mathrm{ha}$ na ausência da adubação verde, na presença desta caiu para sòmente $+69 \mathrm{~kg} / \mathrm{ha}$. Por sua vez, tendo sido de apenas $+70 \mathrm{~kg} / \mathrm{ha}$, na ausência, elevou-se a +597 kg/ha, na presença do potássio. 
Quadro 1. - Produções de feijão, em quilogramas por hectare, obtidas na experiência de adubação verde com ervilha-de-vaca realizada em Capão Bonito, na qual essa adubação foi testada na ausência e na presença dos elementos minerais indicados, tendo todos os canteiros recebido dose uniforme de fósforo

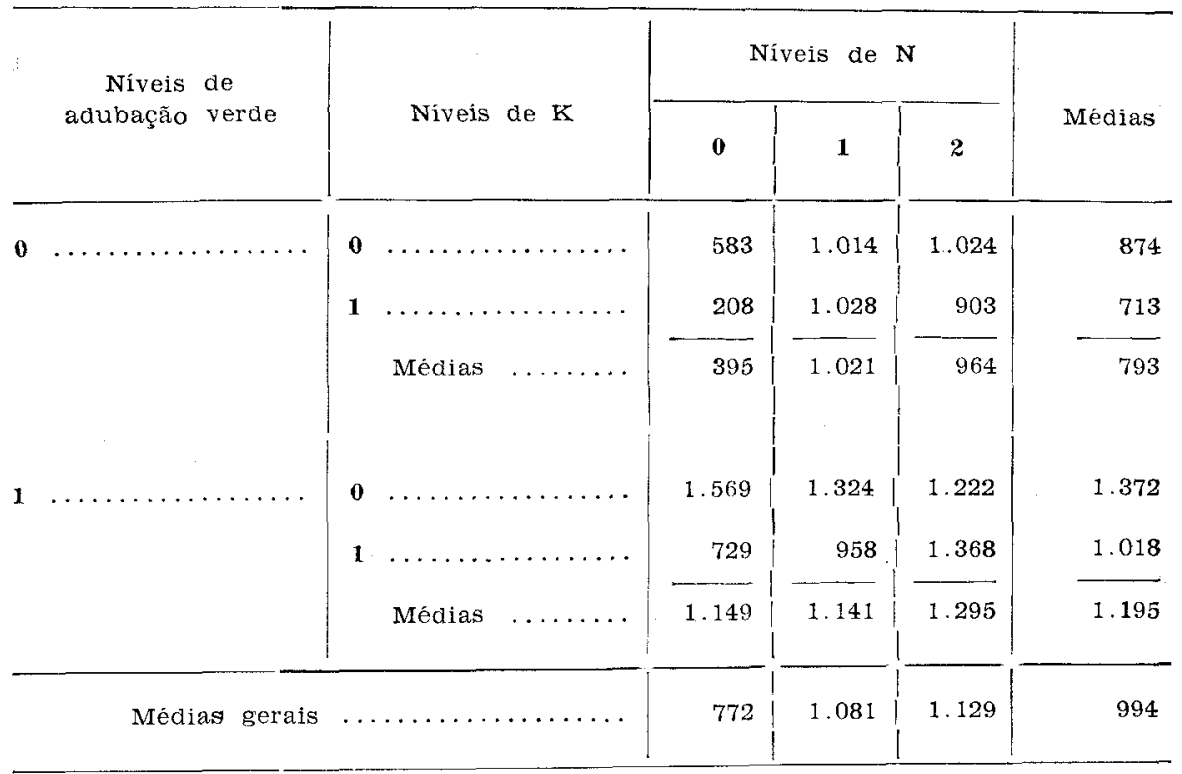

O efeito médio do potássio foi negativo (-258 kg/ha). A presença da adubação verde contribuiu para aumentar a depressão causada pelo potássio, ao passo que a da dose 1 de nitrogênio a tornou menos acentuada e a da dose 2 a eliminou. $\mathrm{Na}$ ausência do nitrogênio e na presença de $\mathrm{N}_{1}$ e $\mathrm{N}_{2}$, as respostas ao potássio foram de, respectivamente, $-609,-176 \mathrm{e}+13 \mathrm{~kg} / \mathrm{ha}$.

Quanto à adubação verde, cuja resposta média foi de $+402 \mathrm{~kg} / \mathrm{ha}(+51 \%)$, observa-se que a presença dos adubos minerais a tornou menos necessária. Assim é que seu efeito, tendo alcançado $+754 \mathrm{~kg} / \mathrm{ha}(+191 \%)$ na ausência do nitrogênio, na presença dêste elemento baixou para $+226 \mathrm{~kg} / \mathrm{ha}(+23 \%)$. Por outro lado, a presença do potássio o fêz cair de $+498 \mathrm{~kg} / \mathrm{ha}$ $(+56 \%)$ para $+305 \mathrm{~kg} / \mathrm{ha}(+43 \%)$. Deve-se lembrar que a adubação verde prejudicou apreciàvelmente os "stands" do feijoeiro. Não fôra isso, e certamente teriam sido ainda maiores os aumentos de produção que ela proporcionou quando empregada na ausência do nitrogênio ou do potássio. 
ConClusõ̃s - Nas condiçōes da presente experiência, conduzida em solo freqüentemente cultivado e adubado nas culturas anteriores, a aplicação de nitrogênio mineral e a adubação verde com ervilha-de-vaca aumentaram consideràvelmente a produção do feijoeiro, quando usadas na ausência uma da outra. Quanto ao potássio, cujo efeito médio foi negativo, sua presença contribuiu para aumentar o efeito do nitrogênio e diminuir o da adubação verde. SEÇÃO DE LEGUMINOSAS E ESTAÇÃO EXPERIMENTAL DE CAPÃO BONITO, INSTITUTO AGRONOMMICO DO ESTADO DE SÃO PAULO.

GREEN MANURING OF DRY BEANS WITH COW PEA

\section{SUMMARY}

In a factorial experiment conducted in the State of São Paulo on soil fertilized with NPK in the previous crops, the yield of dry beans (Phaseolus vulgaris L.) was considerably increased either by mineral nitrogen or by green manure with cow pea, when used in the absence of one another. The presence of potassium increased the effect of nitrogen but decreased that of the green manure. 